\title{
ФОРМИРОВАНИЕ БУДУЩЕГО ПЕДАГОГА КАК КРЕАТИВНОГО СУБЪЕКТА В СИСТЕМЕ НЕПРЕРЫВНОГО ПЕДАГОГИЧЕСКОГО ОБРАЗОВАНИЯ
}

\section{FORMATION OF THE FUTURE TEACHER AS A CREATIVE SUBJECT IN THE SYSTEM OF CONTINUOUS PEDAGOGICAL EDUCATION}

\author{
M. Shakurova \\ T. Smolyaninova \\ L. Arakelyan
}

Summary: The purpose of the article is to identify and describe the features of the formation of the future teacher as a creative subject, taking into account the specifics of the stage of his professional formation in the system of continuous pedagogical education. The research methodology consists of ontological, personality-oriented, system and subject approaches. The article notes that creativity as a manifestation of subjectivity can be actualized, or exist in the form of potency (the creative potential of the subject), or acquire latent forms (in the period of non-demand). It is emphasized that the maintenance of creativity as an essential characteristic and function of the individual and the subject is one of the tasks of the system of continuous pedagogical education, primarily at the stage of pre-professional and professional training. The author substantiates the conclusion that the formation of creative subjectivity should be based on scientifically based ideas about the genesis of creativity as an essential characteristic of the individual; on the existence of a direct relationship between the development of creativity and the formation of experience; on the degree of inclusion of the future teacher in a wide range of types and areas of activity.

Keywords: continuing education system, future teacher, creativity, creative subjectivity.
Шакурова Марина Викторовна

Д.п.н., профессор, Воронежский государственный педагогический университет

shakurova@mail.ru

Смольянинова Татьяна Сергеевна

Аспирант, Воронежский государственный педагогический университет

t.smolyaninova@inbox.ru

Аракелян Лидия Сергеевна

Воронежский государственный педагогический университет

arakelyanlidia@gmail.com

Аннотация: Цель статьи - выделить и описать особенности формирования будущего педагога как креативного субъекта, учитывая специфику этапа его профессионального становления в системе непрерывного педагогического образования. Методологию исследования составили онтологический, личностно-ориентированный, системный и субъектный подходы. В статье отмечено, что креативность как проявление субъектности может актуализироваться, либо существовать в виде потенции (творческий потенциал субъекта), либо приобретать латентные формы (в период невостребованности). Подчеркивается, что поддержание креативности как сущностной характеристики и функции личности и субъекта - одна из задач системы непрерывного педагогического образования, прежде всего, на этапе допрофессиональной и профессиональной подготовки. Обосновывается вывод 0 том, что формирование креативной субъектности должно опираться на научно обоснованные представления 0 генезисе творчества как сущностной характеристики личности; о наличии прямой зависимости между развитием креативности и формированием опыта; о мере включения будущего педагога в широкий спектр видов и направлений деятельности.

Ключевые слова: система непрерывного образования, будущий педагог, творчество, креативная субъектность.

профессионального образования. В этой связи возрастает востребованность непрерывного педагогического образования. «Целью данной системы является создание благоприятных условий для развития личности педагога в различные периоды жизни (профессиональной подготовки, профессиональной деятельности)» [1]. Это еще одна попытка найти адекватные, эффективные, комплексные средства, взаимодействуя с которыми развивающийся профессионал смог бы совершенствовать собственную субъектность, обогащать и выстраивать личность.

Цель статьи - выделить и описать особенности формирования будущего педагога как креативного субъек- 
та, учитывая специфику этапа его профессионального становления в системе непрерывного педагогического образования. В понимании творчества мы будем следовать онтологическому подходу, в центре внимания которого анализ сущности творчества и креативности, деятельностные выражения которого - лишь одно из возможных проявлений. Онтологический подход востребован и в оценке сущности человека и его основных проекций (субъект, личность, индивидуальность). Также в основу исследования положены принципы личностноориентированного, субъектного и системного подходов.

Развитие человека не сводимо к развитию его личности. По мнению А.Б. Орлова, личность является не субъектом, а атрибутом человеческой сущности. «По отношению к подлинному субъекту личность человека выступает в качестве внешней, состоящей из мотивационных отношений "оболочки", которая может как транслировать, так и трансформировать подлинные субъектные проявления человека» [6, с. 58]. В.В. Сериков полагает, что личность есть способность человека занимать в мире определенную позицию, выраженное субъектное отношение к миру. Его можно описать через систему функций (избирательность, рефлексия, поиск смыслов, ответственность, волевая регуляция, творческий потенциал, способность к автономному поведению и др.) [8].

Субъектность (самость, сущность) - базовая характеристика «внутреннего Я» человека. Самость нельзя объективировать в полной мере. Любые предпринимаемые попытки представить тот или иной образ самости (самость есть синтез, целостность, центр и т.п.) не отражают ее сущности. С.Л. Рубинштейн отмечал: «Личность во всем многообразии своих проявлений не может <...> сомкнуться в одно внутреннее связное целое. Она разделяется на две гетерогенные составные части. Субъект - то, что в личности есть она "сама", остается за деятелями как его проявлениями, он им трансцендентен. Направлениями его деятельности можно определять и формировать его, но не сводить к этому!» [7, с. 93-94].

Определенным образом приблизиться к пониманию субъектности, а также природы континуума «субъектность - личность» позволяет теория «Я-концепции». Центральным элементом «Я-концепции» выступает образ «Я», который является результатом выделения человеком себя из окружающей среды и дает ему ощущение себя как субъекта своих состояний, свойств, процессов, личности, ощущение идентичности с самим собой на протяжении всей жизни.

Неразличение внешнего и внутреннего «Я» в традиционной отечественной психологии и педагогике имело следствием отождествление человека с его личностью при неизбежной потере понятия подлинного субъекта.
Современные психологические исследования обращают внимание на возможные негативные следствия подобного отождествления. Это и ложное или стереотипное самоотождествление («Я» есть та или иная личностная функция, социальная роль, маска или результат идентификации с ожидаемым со стороны социального окружения образом). В качестве проблемы выступает и неразвитость рефлексии как диалога между внутренним и внешним «Я», как правило, в связи с неумением или неспособностью «слышать» именно голос внутреннего «Я». Возможно также постоянное искажение субъектности (вплоть до ее полного нивелирования) под влиянием массированного личностного становления (у А.Б. Орлова доминирование процесса персонализации над процессом персонификации [6]).

Очевидно, что целостность и эффективность подготовки педагога в системе непрерывного образования, будет определяется тем, насколько удастся создать условия как для развития субъектности, так и для личностного развития с учетом вышеназванных и иных возможных проблем. При этом выделяются три аспекта анализа и моделирования:

- характеристики системы непрерывного педагогического образования, позволяющие создавать позитивные условия для развития как субъектности, так и личности человека;

- характеристики системы непрерывного педагогического образования, позволяющие обеспечить оптимальное сочетание, баланс в развитии субъектности и личности человека;

- характеристики системы непрерывного педагогического образования, позволяющие обеспечить субъектность позиции личности в процессе самостроительства и преобразования самой системы.

Одним из проявлений субъектности выступает креативность. Как и прочие другие характеристики, креативность проявляется как на личностном, так и на субъектном уровне. В чем же возможное различие?

Традиционно в педагогике креативность (творческость, способность к творчеству, творческая активность и т.п.) рассматривались в деятельностном или личностно-деятельностном ключе. Акцент делался именно на внешнюю продуктивность творческого акта, создание продукта творчества, личностные механизмы творческой деятельности.

Креативность как характеристику субъекта представляет онтологический подход, рассматривающий творчество как важнейший родообразующий фактор человечества, творчество как жизнетворчество. Креативность - сущностная характеристика человека, проявляющаяся в диалектическом единстве внутренних (сотворение себя) и внешних (преобразование окружаю- 
щей действительности) проявлений. Основной продукт и основная ценность - сам субъект, его «Я-концепция». Как подчеркивает Г.С. Батищев, креативное отношение есть отношение субъекта к миру как миру проблем-загадок [2]. Креативность не монологична, не моносубъектна, как бы социально и исторически ни был опосредован субъект, но по сути своей межсубъектна, построена на основе глубинного общения.

Креативность как проявление субъектности может актуализироваться, либо существовать в виде потенции (творческий потенциал), либо приобретать латентные формы (в период невостребованности). Длительное латентное состояние, невозможность творчески себя реализовывать приводит к деформации, деградации, потере желания, стремления направлять свою активность на внутреннее и внешнее преобразование. Активность может приобрести адаптивные (приспособительные) формы, следствием которых на личностном уровне выступают социальная апатия, индифферентность, стереотипность и нормативная шаблонность самовыражения и т.п.

Показательный в этой связи результаты одного из проведенных нами исследований, в котором в качестве респондентов участвовали студенты-заочники Воронежского государственного педагогического университета и учащиеся старших классов одной из гимназий г. Воронежа (152 человека). 34,8\% опрошенных гимназистов и 41,0\% студентов без колебания отнесли себя к категории исполнителей. Творческий характер жизнеосуществления удовлетворяет лишь 10 опрошенных гимназистов-«творцов» и 32 опрошенных студентов«творцов» («реализую себя», «вынуждает жизнь», «приходится надеяться на себя», «иначе не могу», «этим достигается возможность человека действовать самому, закалять характер, он становится опытным и уверенным в себе» и т.п.), огорчает соответственно 13 и 2 опрошенных, которые отнесли себя к разряду «творцов» («устала», «иногда это очень обременительно», «радует то, что ты можешь заставить ситуацию играть в свою пользу, но иногда раздражает - получается, что я должна за всех думать» и др.). Исполнительская позиция радует или оставляет равнодушными 19 респондентов-школьников и 13 респондентов-студентов («так легче», «привыкла», «так устроена моя жизнь», «кому-то надо и исполнять» и т.п.). В числе аргументов, которые приводятся опрошенными, не удовлетворенными исполнительским характером своей жизненной позиции, чаще всего встречаются: закрепившийся отрицательный опыт творческого самовыражения («Я очень боюсь, что мое творчество будет подавлено и я буду переживать»); проблемы с формированием и осуществлением рефлексии, ощущаемое как отсутствие диалога с внутренним «Я» («хочется иметь свое "Я", но это не всегда получается»); отсутствие необходимых внешних условий, в частности нет понимания со стороны окружающих, свободы в выборе способа самовыражения («не дают простора для творчества», «я не могу высказать свои мысли, идеи, так как это никого не интересует», «нет возможности выразить себя, от этого постоянно тупеешь» и т.п.). Последний тезис побудил нас попытаться выяснить, как соотносятся между собой мотивы «долженствования» и «желания» в творческом самопроявлении. Очевидно, что первый мотив есть комплексное выражение нормативной установки, тогда как второй отражает субъектную позицию опрашиваемых. Среди тех, кто выбрал позицию «творец», 79,3\% опрошенных руководствуются мотивом «желание», тогда как среди «исполнителей» подобная мотивация свойственна $60,8 \%$ опрошенных.

В результате обработки уточняющих вопросов, мы получили возможность утверждать, что большинство респондентов зависимы от внешнего стимулирования и предпочитают при этом демонстрацию заинтересованности со стороны друзей, семьи, учителей, коллег по работе, общества в целом. Собственная заинтересованность имеет смысл только для 58,0\% опрошенных школьников и $60,2 \%$ опрошенных студентов.

Поддержание креативности как сущностной характеристики и функции личности - одна из задач системы непрерывного педагогического образования, прежде всего, на этапе допрофессиональной и профессиональной подготовки.

На уровне допрофессиональной подготовке как отечественная, так и многие зарубежные системы сориентированы на выявление соответствующей одаренности. Применительно к педагогической профессии не столько проводится предпрофессиональный скрининг, сколько используется широкий набор конкурсов, олимпиад, соревнований и т.п. Отметим, что в данном случае у будущих педагогов выявляется в первую очередь «предметная одаренность», что в итоге может привести к серьезным проблемам, поскольку педагогическая профессия строится на активной коммуникации, способность и готовность к которой, невозможно выявить предлагаемыми заданиями. С точки зрения творческого потенциала возможных абитуриентов данный механизм также уязвим, поскольку большинство заданий и задач, как уже отмечалось, предполагают творческий уровень исполнения, но в рамках предмета. С другой стороны, для выявления более широкого спектра творческих возможностей и общей креативности необходимы специальные методики (в большинстве случаев применительно к педагогической профессии отсутствуют), длительно организованное наблюдение и пробы.

С началом профессиональной подготовки меняется среда жизнедеятельности и окружение молодого человека, при этом система обучения, за редким ис- 
ключением, остается очень близкой школьной. В определенной мере расширяется спектр возможностей для проявления и развития креативности, но, как и в школе, здесь доминирует внеучебная сфера, где в значительной мере присутствуют и выбираются «непрофильные» виды активности либо профессиональные смыслы декларируются организаторами, но не осмысливаются самими участниками. Профессиональные конкурсы, олимпиады, соревнования сохраняются, но существенное их число связаны с профессиональной обученностью, а не развитием личностно-профессиональной позиции и профессиональной воспитанностью.

Как видим, уже при первом приближении видна системная сложность формирования креативной субъектности будущих педагогов. Поиск адекватных решений, на наш взгляд, должен опираться на научно обоснованные теоретические позиции. Остановимся подробнее на нескольких из них.

1. Творчество - скорее правило, чем исключение, но возникает оно очень медленно и постепенно, развивается из более элементарных форм в более сложные (Л. С. Выготский).

В результате многочисленных психологических исследований было доказано, что только на этапе подросткового возраста человек становится полноценным субъектом собственной жизнедеятельности и самостроительства. Именно в этот период «предыстории личности» [3; 11] в полную силу начинают проявляться рефлексивные процессы как разнообразные, не прекращающиеся на интер-уровне диалоги внутреннего и внешнего «Я», личности и субъектности. В отсутствии полноценной субъектности стимулируется личностное развитие, в том числе и воспитательными воздействиями. Более того, именно на этом этапе ребенок уязвим, поскольку, во-первых, нуждается в предъявлении ему однозначно сформулированных ценностей и образцов поведения; во-вторых, не может критически осмыслить предлагаемые образцы; в-третьих, активно пользуется механизмами идентификации и подражания, которые сами по себе могут породить ложное или искаженное самоотождествление. «Кроме того, впечатления, различные эмоциональные состояния, вызванные общением с другими людьми в этом возрасте, в первую очередь сохраняются в памяти, во многом определяя дальнейшее поведение и отношения, существенно влияя на формирующиеся образы "Я". Применив в одном из исследований метод ретроспекции при опросе старшеклассников и студентов, мы получили следующие результаты: у $63,9 \%$ опрошенных воспоминания связаны с негативно окрашенными событиями общения ("невнимание со стороны взрослых", "отношение ко мне как к ребенку", "незаслуженные наказания", "грубость", "плохое настроение взрослых, их ссоры", "одиночество" и т.п.)» [10, с. 69-70].
Отметим, что подобные суждения встречаются в 95 рассказах из 324 (более четверти).

В системе отношений «ребенок-взрослый» существует иная крайность: родители и учителя стремятся найти в ребенке признаки таланта, которые переоцениваются, «додумываются». Преувеличенное внимание к отдельным способностям за счет других форм самопроявления приводят к жесткой идентификации формирующегося «Я» с небесспорным талантом, одной единственной способностью, что также ограничивает и тормозит развитие креативности как сущностной характеристики субъекта, а также субъективности в целом.

Социальная (включая коммуникативную) одаренность, столь необходимая для педагогической профессии, также зависима от этапа взросления. В этой связи представляет интерес исследование, выполненное Т.М. Хрусталевой. Сравнивая особенности социальной одаренности обучающихся младших, средних и старших классов, автор делает вывод о том, что в подростковом возрасте сформированная ранее структура социальной одаренности дополняется проявлениями педагогических склонностей и интересов. У старшеклассников более очевидной становится склонность к педагогическому взаимодействию. С возрастом уменьшается зависимость социальной одаренности от природных характеристик, возрастает значение личностных особенностей. «В подростковом возрасте в процессе общения как ведущего типа деятельности активно развиваются различные элементы взрослости, подросток активно отстаивает свое право на нее. Поэтому важнейшими составляющими социальной одаренности становятся лидерские характеристики (коммуникативные и организаторские способности), а среди личностных детерминант - смелость, независимость, радикализм, доминантность. В юношеском возрасте человек осознает своею неповторимость, уникальность, что приводит к более пристальному вниманию к своему внутреннему миру и психологии других людей. Юноша интегрируется в общество. Это определяет взаимосвязь таких характеристик социальной одаренности, как эмпатийность и творческость, и таких свойств личности, как сензитивность, социабельность и тревожность старшеклассника» [9, с. 173].

2. Креативность находится в прямой зависимости от опыта; нельзя не учитывать субъективный и субъектный опыт ребенка, педагога или родителя.

Под субъективным опытом человека принято понимать сугубо внутреннее образование, базирующееся на чувственно-эмпирическом постижении окружающего мира и самого себя. Субъектный опыт - еще одна сущностная характеристика субъектности, которая развивается и совершенствуется в результате самостоятельного (либо под нежестким руководством) постижения и осво- 
ения мира, как в деятельности, так и в общении.

Пространство непрерывного педагогического образования необходимо наполнить педагогическими смыслами и соответствующими ценностями. Ценность другого человека, саморазвития, образования - лишь немногие из тех, которое необходимы для формирования личностно-профессиональной позиции будущего педагога. Возрастные особенности таковы, что в

- для младших школьников демонстрируемые и формируемые ценности должны быть стабильны, непротиворечивы; по ним живут;

- для подростков важно обеспечить пространство, где ценности нужно выбирать, руководствуясь собственной и общественной целесообразностью (каждый свободен в их использовании до тех пор, пока это не вредит окружающим), ценности должны стать руководством к действию - по ним можно и нужно строить свою жизнь;

- для старшеклассников и молодежи необходимо закреплять установку на то, что ценности - неотъемлемая часть человеческой жизни: Я могу по ним жить, но жизнь не стоит на месте, а, следовательно, Я могу привнести (привнесу!) нечто новое. Вот только очень сложно удержаться от оппозиции и действовать исключительно по уму; не менее сложно понять, что «моя» интерпретация ценна только в том случае, если она значима и для «Другого».

Поднимая данный вопрос, мы руководствуемся убеждением в том, что решать воспитательные задачи может только воспитанный учитель.

Приращение субъектного опыта, по сути, творческий процесс, реализуемый каждым человеком в пространстве своей жизнедеятельности. Для анализа возможностей данного пространства воспользуемся концепцией «экологии человеческого развития», разработанной американским системологом Ури Бронфенбреннером [5]. По мере взросления человека расширяется его окружение, он становится участником все новых сеттингов, то есть осваивает новые виды деятельности, роли, систему отношений (совершает, как писал У. Бронфенбреннер, «экологический переход»). При этом процесс перехода, социализации в новых сеттингах идет более успешно и безболезненно, если этот переход происходит не в одиночку, а в сопровождении одного или нескольких участников предыдущего сеттинга («звенья поддержки»); если присутствуют «звенья поддержки» между сеттингами, представленные людьми, уже сформировавшими как с человеком, так и между собой определенные партнерские отношения (родители, друзья, учителя, другие референтные для человека Другие). В данном ключе необходимо переосмыслить и технологически выстроить взаимодействия в системе непрерывного педагогиче- ского образования, вернуться к миссии тьюторов, кураторов, наставников будущего педагога.

Заслуживает внимания и тот факт, что позитивный развивающий эффект участия человека в различных сеттингах возрастает в том случае, когда они находятся в различных культурных (субкультурных) контекстах, отличаются друг от друга по одному или нескольким показателям. В частности, это возможно при организации эффективного социокультурного диалога (диалог между представителями различных культур, различных возрастных групп, различных профессиональных групп и т.п.).

3. Ошибочным является представление о том, что продуктивное развитие креативности субъекта и личности можно обеспечить, исключительно за счет предоставления человеку максимальной свободы, широкого поля деятельности, включив его в многообразные формы самореализации. В теории воспитательных систем [4] доказано положение о том, что нормальное функционирование системы возможно при доминировании нескольких видов деятельности как возможного системообразующего фактора. Стремление уйти от этого ограничения, культивировать все или почти все из существующих в настоящий момент направлений деятельности образовательных организаций, стремясь в большинство из них включить будущего педагога приносят вред как самой системе, так и каждому конкретному человеку, его субъектности. Проблема креативности связана с проблемой полноты проявления человеческой жизни. Понятие полноты жизни включает количественные (расширение связей с обществом, другими людьми) и качественные (упорядоченность связей человека с внешним упорядоченность связей человека с внешним миром; их пропорциональность, гармония, разносторонность, универсальность) характеристики. И теория, и практика доказывают, что увеличение числа связей как самоцель неизбежно приводит к ухудшению их качественных характеристик, закрепление в поведении человека рисунка поверхностного реагирования и участия либо перенасыщения и неизбежной усталости, тревожности.

Таким образом, бедность связей и отношений личности выступает преградой ее развития, тогда как чрезмерное множество связей не развивает ее, угрожает ей конформизмом и потерей самостоятельности. Вариантом решения может стать поиск значимых видов и форм личностной самореализации на основе детального изучения их иерархии в оценке будущего педагога, характера его субъектного отношения и интереса к ним.

Подводя итог, отметим, что проектирование в рамках системы непрерывного педагогического образования процесса формирования креативной субъектности будущего педагога невозможно без понимания природы и 
проявлений субъектности личности и субъектности педагога, самоопределения будущего педагога в пространстве личностных и профессиональных ценностей, оценки собственной позиции по отношению к творчеству в контексте осваиваемой профессии, учета возрастных особенностей социальной одаренности, а также без вни- мания субъектов системы непрерывного педагогического образования к характеристикам пространства приоритетных ценностей, отношений, деятельности внутри системы, его структурирования с тем, чтобы будущий педагог мог реализовать свой потенциал как субъекта профессиональных отношений и их творца.

\section{ЛИТЕРАТУРА}

1. Ипполитова Н.В. Система непрерывного педагогического образования / Н.В. Ипполитова // Вестник Южно-Уральского государственного университета. Серия: Образование. Педагогические науки. - 2018. - Том 10, № 1. - С. 6-12.

2. Даренский В.Ю. Философско-антропологическая концепция Г. С. Батищева: «Человек восходящий» / В.Ю. Даренский // Известия Саратовского университета. Новая серия. Серия Философия. Психология. Педагогика. - 2017. - Том 17, № 2. - С. 135-140.

3. Жизнь как творчество / под ред. Л.В. Сохань, В.А. Тихонович. - Киев: Наукова Думка, 1985. - 304 с.

4. Караковский В.А. Воспитание? Воспитание... Воспитание! / В.А. Караковский, Л.И. Новикова, Н.Л. Селиванова. - Москва : Новая школа, 1996. - 160 с.

5. Коул М. Изучение поведения в контексте: мезогенетический подход / М. Коул // Культурно-историческая психология. - 2015. - Том 11, № 4. - С. $55-68$.

6. Орлов А.Б. Психология личности и сущности человека: парадигмы, проекции, практики / А.Б. Орлов. - Москва : 000 «Издательская группа "Логос"», 1995. -224 c.

7. Рубинштейн С.Л. Принцип творческой самодеятельности : К философским основам современной педагогики / С.Л. Рубинштейн // Вопросы философии. 1989. - № 4. - С. 88-95.

8. Сериков В.В. Личностно-развивающее образование как одна их культурологических образовательных моделей / В.В. Сериков // Известия Волгоградского государственного педагогического университета. - 2016. - № 2. - С. 30-35.

9. Х Хрусталева Т.М. Возрастные особенности проявления социальной одаренности школьников / Т.М. Хрусталева // Сибирский педагогический журнал. 2011. - № 10. - С. 170-175.

10. Шакурова М.В. Антропо-характеристики как средство формирования социокультурной идентичности личности / М.В. Шакурова // Вопросы воспитания. - 2015. - № 2. - С. 64-73.

11. Щукина М.А. Саморазвитие как форма жизнетворчества / М.А. Щукина // Вестник Вятского государственного университета. - 2012. - № 2-1. C. $141-146$

(c)Шакурова Марина Викторовна (shakurova@mail.ru), Смольянинова Татьяна Сергеевна (t.smolyaninova@inbox.ru),

Аракелян Лидия Сергеевна (arakelyanlidia@gmail.com).

Журнал «Современная наука: актуальные проблемы теории и практики»

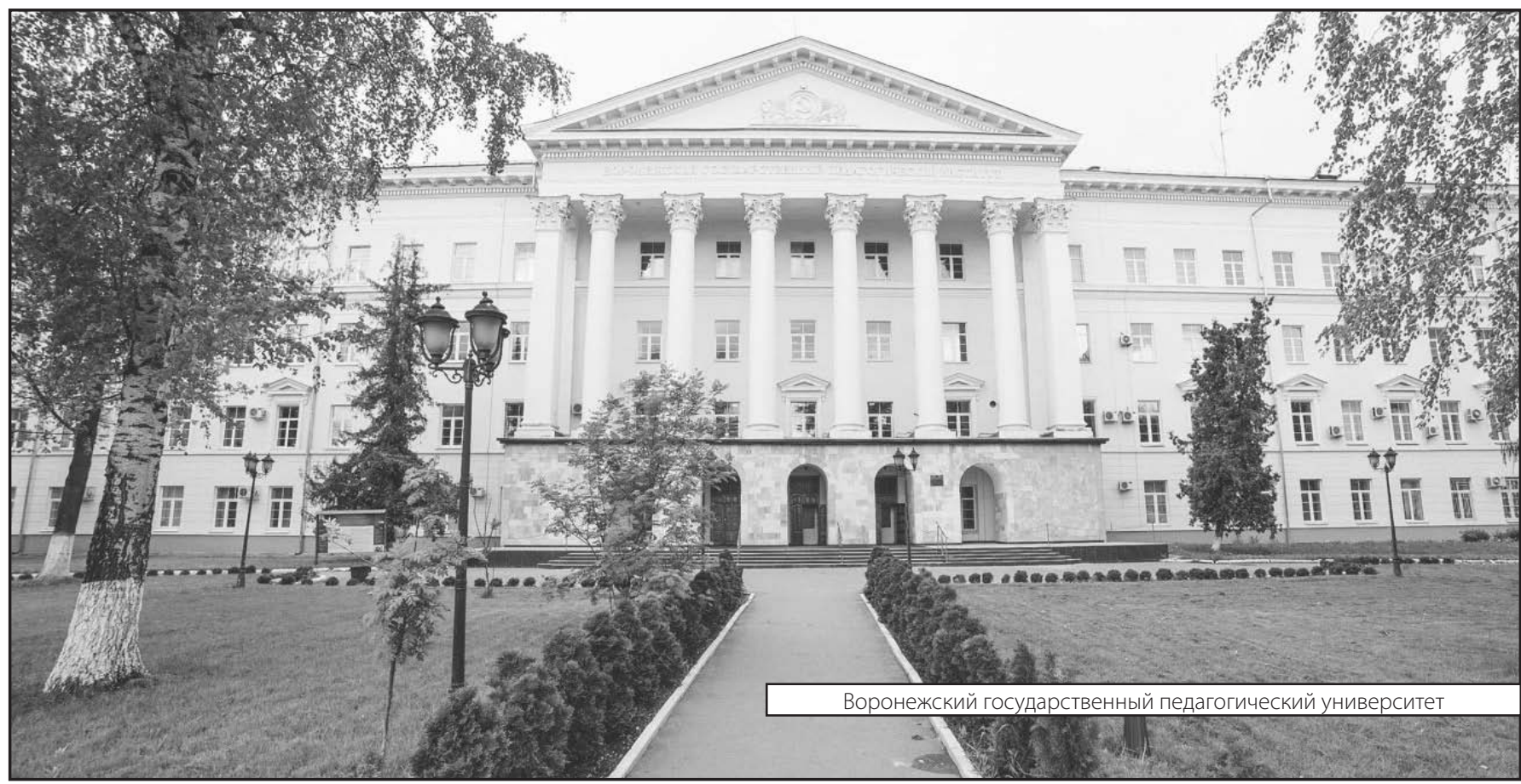

